(3) (1) https://creativecommons.org/licenses/by/4.0/

\title{
ANTROPOLOGIA E EDUCAÇÃO ESCOLAR: A EDUCAÇÃO INDÍGENA, O COMBATE À MISOGINIA, À LGBTTFOBIA E À DISCRIMINAÇÃO CONTRA A CULTURA AFRO- BRASILEIRA
}

\author{
MARCEL DE ALMEIDA FREITAS ${ }^{1}$ \\ ORCID: https://orcid.org/0000-0003-4928-2136
}

\begin{abstract}
RESUMO: O artigo enfoca algumas contribuições da Antropologia para quatro aspectos da educação escolar: a educação escolar indígena, a discriminação contra as mulheres, contra pessoas LGBTT e o preconceito contra práticas culturais e tradições religiosas afro-brasileiras. No que diz respeito à metodologia, foi utilizada a revisão teórica sobre esses temas na interface da Antropologia com a Educação. Aqui o termo escola é entendido como a principal manifestação da educação formal no Ocidente e a partir do conceito de campo educacional, isto é, a partir de suas estruturações históricas, sociais, políticas, econômicas e, notadamente, culturais, perspectiva com a qual a Antropologia pode contribuir bastante. Um dos postulados antropológicos mais importantes para a Educação Escolar é que, ao contrário do que geralmente se acredita no senso comum, o comportamento humano não depende tanto da natureza, mas decorre, sobretudo, da aprendizagem em contextos coletivos. O principal intuito desta contribuição teórica é demonstrar alguns impasses na relação entre escola, campo educacional e cultura brasileira e o quanto a escola ainda não está preparada para o reconhecimento e o acolhimento da diferença e da diversidade. No texto, advoga-se que a Antropologia se volte mais para a educação escolar e que especialmente uma de suas aplicações práticas, a Pedagogia, se abra mais a contribuições do campo antropológico como vem fazendo em relação à Sociologia e à Psicologia, por exemplo.
\end{abstract}

Palavras-chave: Antropologia e escola; misoginia; LGBTTfobia; cultura afro-brasileira; educação indígena.

\section{ANTHROPOLOGY AND SCHOOL EDUCATION: INDIGENOUS EDUCATION, THE FIGHT AGAINST MISOGYNY, LGBTT-PHOBIA, AND DISCRIMINATION AGAINST AFRO-BRAZILIAN CULTURE}

\begin{abstract}
The article focuses on some contributions of Anthropology to four aspects of schooling education: the indigenous schooling, the discrimination against women and LGBTT individuals, and the prejudice against Afro-Brazilian cultural practices and religious traditions. Regarding the methodology, we did a theoretical review about these themes in the interface of Anthropology and Education. Here the concept of school is understood as the main manifestation of formal education in the West and from the concept of educational field, that is, from its historical, social, political, economic and, particularly,
\end{abstract}

\footnotetext{
${ }^{1}$ Universidade Federal de Minas Gerais (UFMG). Belo Horizonte, MG, Brasil. <marcel.fae.ufmg@gmail.com>
} Educação em Revista|Belo Horizonte|v.37|e26064|2021 
cultural structures, a perspective in which Anthropology can strongly contribute. One of the most important anthropological postulates for School Education is that, contrary to common sense, human behavior does not depend so heavily on nature, but results mainly from learning in collective contexts. The main aim of this theoretical contribution is to present some challenges in the relationship among school, educational field, Brazilian culture and the extent to which school is not yet prepared to recognize and accept difference and diversity. In this text, we propose that Anthropology should turn more to school education and that, especially one of its practical application, the Pedagogy, could be more open to contributions from the anthropological field as it has been occuring, for instance, with Sociology and Psychology.

Keywords: anthropology and school; misoginy; LGBTTphobia; afro-brazilian culture; indigenous education.

\section{ANTROPOLOGÍA Y EDUCACIÓN ESCOLAR: EDUCACIÓN INDÍGENA, EL COMBATE A LA MISOGINIA, A LA LGBTTFOBIA Y A LA DISCRIMINACIÓN CONTRA LA CULTURA AFROBRASILEÑA}

RESUMEN: El artículo enfoca algunas contribuciones de la Antropología para cuatro aspectos de la educación escolar: la educación escolar indígena, la discriminación contra mujeres, contra personas LGBTT y los prejuicios contra prácticas culturales y las tradiciones religiosas afrobrasileñas. Hablando de la metodología, fue utilizada la revisión teórica sobre esos temas en su interfaz con la educación. Aquí el término escuela es comprendido como la principal manifestación de la educación formal en el Occidente y desde el concepto de campo educacional, o sea, desde sus estructuraciones históricas, sociales, políticas, económicas y, sobre todo, culturales, mirada desde la cual la Antropología puede contribuir más. Una de las suposiciones antropológicas más importantes para la Educación Escolar es que, al contrario de lo que en general se cree en el sentido común, el comportamiento humano no depende tanto de la naturaleza, sino adviene, sobre todo, del aprendizaje en contextos colectivos. El principal reto de ese aporte teórico es demostrar algunos obstáculos en la relación entre escuela, campo educativo y cultura brasileña y hasta qué punto la escuela aún no está preparada para el reconocimiento y la aceptación de la diferencia y de la diversidad. En el texto es propuesto que la Antropología se vuelva más hacia la Educación y, especialmente una de sus aplicaciones prácticas, la Pedagogía, esté más abierta a las contribuciones del campo antropológico como hizo con relación a la Sociología y a la Psicología, por ejemplo.

Palabras clave: antropología y escuela; misoginia; LGBTTfobia; cultura afrobrasileña; educación indígena. 


\section{INTRODUÇÃO}

Conforme Mariza Peirano (1983), junto à Ciência Política e à Sociologia, a Antropologia constitui uma das três ciências sociais que buscam entender o ser humano em convivência coletiva, desde o nível macroestrutural das grandes sociedades ao nível micro das relações face a face nos grupos. Assim, o texto apresenta algumas contribuições da Antropologia para quatro grandes temáticas em voga na educação escolar e muito prementes no contexto brasileiro atual de ressurgimento de posturas, inclusive oficiais, anti-democráticas e intolerantes: a educação voltada para os povos indígenas, o enfrentamento da discriminação contra mulheres e contra pessoas LGBT'Ts na escola e o preconceito contra práticas culturais e tradições religiosas afro-brasileiras.

Até chegar a essa interlocução da Antropologia com a Educação (ou com o Serviço Social, por exemplo), percorreu-se um longo caminho para que tal área de conhecimento entendesse que "povos simples" não eram sinônimo de "povos atrasados", bem como para que abandonasse o caráter evolucionista dos primeiros teóricos do século XIX, que enxergavam a sociedade europeia como mais "adiantada" e, por isso, encarregada de "civilizar" outros povos. Os temas mais comuns no início da sistematização do pensamento antropológico eram questões ligadas à religião e à organização familiar dos povos (LAPLANTINE, 1994).

Um dos postulados antropológicos mais importantes, inclusive para a Educação Escolar, é que, ao contrário do que comumente se acredita no senso comum e em oposição ao que é veiculado pela mídia, o comportamento humano não depende tanto da natureza como acontece com outros animais; o que mais o determina - desde as maneiras de pensar, passando pelos gostos subjetivos até as emoções mais profundas - é o fato de o homem viver em sociedade submerso em uma cultura. Portanto, a Antropologia ocupa-se, entre outras coisas, de entender a cultura humana e como ela influencia outros fenômenos da vida, como a arte, a religião e a educação, por exemplo.

Segundo Neusa Gusmão (2015), é por esse motivo que em qualquer sociedade existe algum tipo de aprendizagem inerente às diversas vivências cotidianas coletivas. Dessa forma, a escola não configura o único local onde a educação se realiza; entretanto, neste trabalho, é enfocada somente a educação institucionalizada, visto ser ela o principal contexto que estabelece a distinção entre um sujeito que ensina (o/a docente) e um sujeito que aprende (o/a discente), estipulando que o processo deva se dar nesse espaço específico, a partir de conteúdos e de práticas intencionalmente definidas para tal objetivo.

Especificamente no contexto de educação formal, vem sendo crucial nos últimos anos a interferência da Antropologia, embora, até o momento, sejam tímidas as imbricações entre a Pedagogia (a educação sistematizada propriamente) e a Antropologia, tendo em vista a forte influência do individualismo liberal e das correntes filosóficas positivistas próprias do mundo ocidental no primeiro campo. Em razão disso,

[...] a forte presença da psicologia tem levado o processo educativo a centrar-se na ação educativa mais do que no campo educacional. [...]. Ação educativa é de ordem prática e mais prescritiva. Objetiva interiorizar sentimentos, hábitos, valores inerentes à ordem social. Diz respeito às teorias positivistas de sociedade. Campo educacional busca uma visão compreensiva da realidade social, mais interpretativa, ordenada pelo campo político e pelas relações de poder. Tem por paradigma a noção de conflito. Considera a dinamicidade da produção e reprodução do mundo social (GUSMÃO, 2015, p. 22).

Assim, neste texto, o principal modo de manifestação da educação formal no Ocidente, a escola, é compreendido a partir do conceito de campo educacional, ou seja, a partir de suas estruturações mais abrangentes de caráter histórico, social, político, econômico e, especialmente, cultural, visão com a qual a Antropologia pode contribuir de modo mais profícuo. Com efeito, o principal objetivo desta contribuição teórica é evidenciar alguns impasses da relação entre escola, campo educacional e cultura brasileira e o quanto a escola não está ainda preparada para o reconhecimento e o acolhimento da diversidade e da diferença. No que se refere à metodologia, foi usada a revisão teórica sobre os referidos temas em articulação com a educação. 


\section{ANTROPOLOGIA DA EDUCAÇÃO: ALGUMAS DEFINIÇÕES E BREVE HISTÓRICO}

A Antropologia da Educação teve início quando as ciências sociais, de modo geral, e a Antropologia, em especial, passaram a criticar o formalismo da Pedagogia tradicional (FORQUIN, 1993) a partir dos marcos teóricos críticos, inclusive direcionados à própria Antropologia clássica, por parte da Antropologia Cultural. Neste cenário, o conceito de cultura foi fulcral. De fato, foi no bojo da crítica ao evolucionismo e ao difusionismo, do antropólogo alemão radicado nos Estados Unidos Franz Boas, que se consolidou o conceito de cultura:

\footnotetext{
A concepção boasiana de cultura tem como fundamento um relativismo de fundo metodológico, baseado no reconhecimento de que cada ser humano vê o mundo sob a perspectiva da cultura em que cresceu - em uma expressão que se tornou famosa, ele disse que estamos acorrentados aos "grilhões da tradição". [...]. A percepção do valor relativo de todas as culturas - a palavra aparece agora no plural, e não no singular, como no caso dos evolucionistas - servia também para ajudar a lidar com as difíceis questões colocadas para a humanidade pela diversidade cultural [...]. Segundo Boas, para se compreender as diferenças observáveis entre populações de origens diferentes, era importante considerar não suas supostas características "raciais': e sim o efeito de outras variáveis, como o meio ambiente e especialmente as condições sociais em que vivem essas populações. [...]. Era nesse sentido que ele rejeitava também a pretensa validade científica dos testes de inteligência, então usados para "provar" a inferioridade das pessoas "de cor" em relação aos brancos (BOAS, 2005, p. 18-19).
}

A Pedagogia tradicional era acusada de ensinar conteúdos presos a modelos e a convenções que induziam formas totalizadoras de ser, pensar, agir e de conhecer. Outra crítica era que os conteúdos da educação clássica seriam atemporais e transculturais, descontextualizados e des-historicizados. As formas de expressão e de pensamento, as referências estéticas, os valores morais próprios da sociedade ocidental industrializada, enfim, eram transmitidos nos processos de escolarização como se sempre tivessem existido. Nesses termos, sobretudo a partir da Antropologia Cultural norte-americana, a Antropologia da Educação já conta com algumas décadas de existência no âmbito acadêmico:

As a subdivision of the wider field of anthropology, anthropology of education has been in existence for many decades. In the United States, for instance, German-born Franz Boas founded the first department of anthropology of the Americas at Columbia University. Here research in the field of anthropology of education began in the 1930s in Teachers College, the graduate center of education and education-related disciplines. The name of the current graduate program at Columbia University is not anthropology of education but rather anthropology and education. [...] the goal of its activities has been the use of anthropological approaches (sometimes uncritically) to reflect (critically) in regard to education and its practices (TADDEI; GAMBONI, 2016, p. 29).

Assim, para se tornarem ensináveis e didáticos, os conteúdos científicos e os conhecimentos humanísticos muitas vezes são subordinados a uma profunda descontextualização e simplificação, perdendo os laços com a cultura de origem para se tornarem elementos vazios de uma "cultura escolástica" abstrata, solta no tempo e no espaço. Essa cultura seria muito similar, conforme Bourdieu e Passeron (1990), à cultura das classes dominantes, daí que a escola seria o veículo por excelência não de ascensão social, mas sim de reprodução das desigualdades.

Logo, o pleno alcance e a apreensão das regras e dos conceitos culturais disponibilizados pela escola, especialmente os relativos às artes eruditas e à cultura letrada, dependem da prévia internalização desses conhecimentos e valores no seio familiar. Com efeito, nesta perspectiva, os sistemas de ensino, ao cobrarem de todos - nos exames - aquilo que só alguns trazem na sua bagagem cultural, reproduzem as desigualdades socioculturais. Em resumo, a escola, diferente do que postula o senso comum e as teorias neoliberais, não oferece acesso democrático a saberes e competências para todos, mas reforça as distinções de capital cultural que existem na sociedade mais ampla (BOURDIEU; PASSERON, 1990).

Forquin (1993), por sua vez, contra a descontextualização universalista dos currículos e da didática, mostra que a Antropologia da Educação contemporânea contrapõe demandas por funcionalidade, pertinência e realismo às práticas e aos conteúdos pedagógicos, entendendo a educação 
de forma ampla, como preparação para a vida em sociedade e não somente como introjeção de repertórios isolados e abstratos, meramente canônicos.

Embora seja antigo, o diálogo entre Educação e Antropologia ainda é um campo em formação, consolidando-se na interface dessas duas áreas das ciências humanas, cujo eixo norteador é, especialmente, a apropriação por parte dos pesquisadores em Educação dos recursos metodológicos reunidos sob o nome de Etnografia(s). Isso faz com que, eventualmente, as interações entre Educação e Antropologia sejam problemáticas, como salienta Simoni Guedes (2014).

Ainda que tenham ficado ausentes a temática da educação indígena e aquelas ligadas a gênero e orientação sexual, esta obra se insere no amplo contexto de novas temáticas que surgem no campo da Educação, que vem solicitando aproximações com outras ciências humanas, como é o caso da Antropologia, seja em termos metodológicos ou teórico-conceituais. Portanto, o trabalho pode ser visto como a demarcação da necessidade de maior apropriação de temáticas educacionais por parte dos antropólogos e, por outro lado, da premência de que a Educação se enriqueça com teorias e com recursos metodológicos antropológicos, favorecendo o diálogo entre ambas as áreas.

Campo aqui é entendido tal como preconiza Pierre Bourdieu (1988). Noção basilar na obra desse sociólogo, campo é o espaço de práticas específicas, relativamente independente, dotado de história própria; orienta o movimento dos agentes, definindo um universo de questões, referências e marcas culturais. O campo é estruturado pelas relações objetivas entre as posições ocupadas pelos agentes e pelas instituições e determina o modo de suas relações. O que configura um campo são as posições, as lutas concorrenciais e os interesses dos agentes. Tais lutas acontecem tanto dentro de cada campo, como externamente, dos campos entre si. Quando se refere à luta e a campos antagônicos, Bourdieu situa-os em relação a um poder. O campo é estruturado a partir das relações de poder e da oposição de forças distribuídas entre posições dominantes e posições dominadas dos sujeitos, posição esta que varia segundo o capital simbólico, social, econômico e cultural dos agentes.

Bem antes dessas teorizações, no princípio do século XX, com pensadores como Émile Durkheim, por exemplo, estudos nas ciências sociais acerca da educação formal e sobre a escolarização já enfatizavam que a educação deveria ter como meta fundamental estimular em cada indivíduo o aspecto gregário, a noção de ser membro de uma coletividade definida no espaço e no tempo. Prioritariamente, a educação deveria significar a perpetuação de uma cultura, o que constitui o cerne de uma sociedade específica, por meio do processo de socialização. Nesses termos, as ciências sociais constataram que "[...] a primeira tarefa da educação é fazer com que a criança se conforme à cultura no interior da qual ela vai crescer: a escola tem o dever moral de inculcar na criança as tradições que refletem mais especificamente o espírito da nação" (FORQUIN, 1993, p. 125).

A partir da década de 1970, sobretudo nos países que haviam sido colônias de nações europeias, e partindo de grupos historicamente silenciados - negros, mulheres, homossexuais, indígenas, ciganos etc. -, proposições defensoras de uma educação formal mais "adaptada" e respeitosa às peculiaridades dos diferentes grupos e/ou lugares inspiraram críticas à educação escolar, acusada de apagar as culturas e os saberes locais. Na análise de Gusmão (2015), o problema com posturas polarizadas é que elas tratam as sociedades atuais como se fossem monolíticas, desconsiderando que todas as sociedades estão em algum grau de relações com outras, vizinhas ou não, apresentando mutações e conflitos internos; interceptadas por contraditórias correntes ideológicas e de pensamento, são permanentemente instáveis. Logo, o pluralismo cultural não diz respeito somente à relação entre distintas nações, mas faz parte da realidade no interior de cada sociedade.

$\mathrm{Na}$ literatura educacional produzida ao longo das décadas de 1960 e 1970 sobre o fracasso escolar e sobre as assimetrias de desempenho conforme a origem social dos estudantes, na esteira da Sociologia bourdieusiana, a denominada teoria culturalista teve lugar privilegiado. Esta debita tais desigualdades às questões culturais pertencentes aos indivíduos provenientes de diferentes classes sociais, bem como às diferenças de socialização na vida familiar. Dessa forma, muitos sujeitos de certos grupos sociais, em comparação à maioria dos oriundos de outras classes ou grupos, se mostrariam mais próximos das demandas, rotinas, práticas e, principalmente, conhecimentos escolares, o que favoreceria (mas não determinaria) os primeiros a terem melhor desempenho escolar.

Sendo assim, crianças de classes sociais menos favorecidas cultural e economicamente estariam mais propícias ao fracasso escolar pelo fato de apresentarem um déficit cultural, o que, por seu 
turno, traria efeitos na apreensão cognitiva em geral. Entretanto, muitos teóricos alegam que essa questão não tem ligação com o fato de as classes populares terem uma "cultura pobre", como usualmente se pensa, mas, sim, com o fato de os elementos que estruturam seu conjunto cultural não serem valorizados pela sociedade mais ampla e, portanto, não integrarem os programas e os currículos instituídos como acadêmicos e/ou escolares (FORQUIN, 1993).

Um indígena que entra em um curso de Medicina, por exemplo, dificilmente irá se deparar com aprendizados ligados aos conhecimentos de plantas, chás e ervas, adquiridos com seus antepassados. Ele irá se deparar com modelos de conhecimentos farmacológicos alopáticos, ao passo que o estudante de pais químicos, no mesmo curso, já estará, de certa forma, familiarizado com alguns termos, conceitos e teorias científicas que ali circulam. Assim, a questão do déficit cultural não é tanto quantitativa, mas sim qualitativa: quais elementos culturais são valorizados, quais elementos são negligenciados e/ou invisibilizados na educação escolar.

Muitas vezes, essa "outra" cultura é até estigmatizada e desconstruída pela ciência dita canônica. Em função disso, é comum, ao longo da socialização, o fenômeno chamado pelos antropólogos de aculturação: os indivíduos são incentivados a abandonar certos saberes e/ou crenças, vistos como subculturas e/ou superstições, em favor de uma cultura dominante (TOSTA; ROCHA, 2009). Porém, mormente no campo das ciências humanas, essas subculturas, dentro dos espaços educacionais, podem se tornar "cultura de resistência" e, não raro, provocar transformações na cultura escolar e no conhecimento mais geral, recolocando em novos ou em outros termos alguns conteúdos curriculares.

Instaura-se a problemática do currículo comum face às demandas por currículos contextuais e diferenciados. É o que acontece, por exemplo, na educação indígena ou na educação quilombola, a chamada Pedagogia da Pertinência, centrada na comunidade e nos elementos da vida local, voltando-se para um pluralismo radical no que concerne ao currículo. Alega-se que, ao longo da história, a emancipação das massas esteve necessariamente ligada a um projeto universal de escolarização basicamente unificado, reivindicando-se o acesso de todos aos mesmos componentes do currículo e almejando-se uma pretensa igualdade de oportunidades aos vários sujeitos.

No caso da Pedagogia ancorada na pós-modernidade, algumas de suas implicações educacionais e políticas são questionáveis, sobretudo as vinculadas ao conceito idealizado de comunidade. Hoje não mais existe a situação ideal de um indivíduo que pertence a um único e coeso grupo, especialmente na realidade das grandes metrópoles. Nesses espaços, cada pessoa está inserida, de modo voluntário ou não, em uma pluralidade de coletividades, não raramente algumas contraditórias entre si, cujos valores podem ser diametralmente divergentes entre si. Sendo assim, a realidade social é cada vez mais fluida e multiforme, na qual o indivíduo se apoia em distintos recursos, valores e referências. Nesse sentido, falar em um currículo pluricultural sempre será arbitrário, sendo alguns conhecimentos privilegiados e outros, negligenciados.

Forquin (1993), então, problematiza que, mesmo nos casos de grupos minoritários com identidades e limites relativamente fixos, como é o caso dos ciganos na Europa ou dos coreanos no Brasil, seria o caso de mantê-los marginais à educação formal mais geral dada ao restante da sociedade? Que competências, elementos cognitivos e culturais, futuramente, esses indivíduos teriam para transitar na sociedade, disputar postos de emprego, interagir, comunicar-se, enfim?

Ministrar a todos os estudantes em idade escolar de um país um mínimo de conhecimentos básicos, de referências, símbolos e valores comuns é uma demanda política e ética indispensável. Foi sobre esse pilar de sustentação que o ensino público foi edificado no começo do século XX, pressupondo o acesso de todos (ainda que teoricamente) a um núcleo de vivências cognitivas. Por outro lado, os diversos movimentos sociais vieram problematizar, a partir do fim do mesmo século $\mathrm{XX}$, que as peculiaridades étnicas, religiosas, socioeconômicas, de gênero, de orientação sexual, dentre outras, não podem ser silenciadas nesse processo (TOSTA; ROCHA, 2009). É com o dilema frente a essa questão, indissociavelmente vinculada ao exercício da cidadania, que a Antropologia da Educação se depara mais recentemente.

O cerne da questão não é excluir a diferença dentro da educação escolar - as especificidades tanto não podem ser apagadas por um sistema educacional monológico, macroestrutural e autoritário, quanto também não pode haver a redução do sujeito a uma única identidade que o prive do desenvolvimento intelectual e da ampliação dos conhecimentos. Assim, pelo fato de um aluno pertencer 
a um grupo, a escolarização mais abrangente não pode se isentar de lhe ministrar certas teorias ou conhecimentos históricos que, arbitrariamente, a escola julgue não dizer respeito à sua realidade imediata e cultural; não se tem o direito de restringir sua educação formal ao chamado "localismo".

No que diz respeito à epistemologia, a Antropologia da Educação sugere aos educadores questionar o que é considerado "próximo" e o que é visto como "distante" em se tratando dos contextos reais, ou seja, "[...] como não ver, com efeito, que a verdadeira compreensão do meio imediato passa justamente pela mediação dos saberes mais gerais e mais abstratos?” (FORQUIN, 1993, p. 134). Dessa maneira, obrigatoriamente, a educação precisa conduzir o aluno à transição de uma visão de mundo mais etnocentrada, intuitiva e operacional para uma mais descentrada, conceitual e global, processo cognitivo este mediado pelas categorias, modelos e fórmulas mais gerais e abstratas. Em síntese, a escolarização deve ajudar os sujeitos a realizarem a passagem do lúdico ao lógico, certamente que sem a desvalorização e o abandono do primeiro elemento.

Se a educação radicalmente particularista e contextual é criticada pelo risco de certo rebaixamento dos níveis de exigência de desempenho e de abstração, o seu oposto, a educação livresca e canônica, também é desaprovada, nomeadamente pelos antropólogos da educação pós-estruturalistas, pelo fato de ser arbitrária, já que as/os educadoras/es conservam a prerrogativa de definir o que é pedagógica e culturalmente relevante (ou não) de ser ensinado/aprendido. Como mostra Dayrell (2001), tal arbitrariedade aliada à redução da solidariedade coletiva pode gerar frustração e experiências educacionais negativas, fazendo com que a escola seja vista como espaço que se deve frequentar meramente por obrigação, sendo suas rotinas vividas como simples burocracias, sem real relação com a vida dos sujeitos.

Esse processo de declínio educativo, em parte resultante do crescente individualismo nas grandes cidades, pode conduzir a uma ainda maior anomia (descrédito e desprendimento para com os valores sociais) e, no extremo, fomentar práticas violentas, sejam simbólicas (rejeição aos conteúdos escolares e à ciência) ou físicas (agressão a colegas, professores etc.). Tal processo é, ao mesmo tempo, efeito e causa do abandono do objetivo essencial da escola, que é socializar os indivíduos, e da ênfase neoliberalizante no sucesso individual, visto como inserção no mercado de trabalho. Portanto, uma educação inclusiva deve buscar congregar saberes comunitários e imediatos a conhecimentos mais teóricos e abstratos (DAYRELL, 2001).

\section{QUATRO ASPECTOS ESCOLARES PARA OS QUAIS A ANTROPOLOGIA PODE CONTRIBUIR}

Algumas das realidades escolares específicas para as quais a Antropologia pode contribuir ainda são pouco exploradas, como, por exemplo, a educação dos povos nativos - não somente do Brasil, mas da América Latina em geral -, as questões de gênero - especialmente a discriminação contra o sexo feminino nos contextos educacionais -, a temática da sexualidade e nesta, principalmente, a discriminação contra sujeitos LGBTTs, e a discriminação étnico-racial contra manifestações culturais, especialmente religiosas, de matriz africana, preconceito este evidente nos livros didáticos e nos currículos, por exemplo.

No que se refere à Educação Indígena, no começo da década de 1990, diversas associações civis e entidades coletivas, capitaneadas pela União das Nações Indígenas (UNI), tomam para si a questão em referência, buscando entender suas problemáticas, questionar sua complexidade, repensar os direcionamentos que estavam tomando e, sobretudo, apoiar e defender os remanescentes dos primeiros povos, então ameaçados de extinção (SILVA, 2001). Dentre essas frentes, a educação escolar indígena foi uma das mais precípuas.

Os indígenas brasileiros possuem processos de escolarização próprios que, ainda que transmitam conhecimentos mais gerais e consagrados da sociedade ocidental, se particularizam por preservar os modos de ver o mundo e de fazer tradicionais, bem como as línguas nativas. Este ensino específico é ministrado por outros indígenas que cursaram uma modalidade particular de magistério, a Licenciatura Indígena, que os habilita a atuarem como professores nos ensinos Fundamental e Médio dentro de suas aldeias de origem.

Os cursos de formação desse professorado específico são baseados na Pedagogia da Alternância, ou seja, os indígenas deixam as aldeias, vão para as universidades, frequentam aulas 
intensivamente por cerca de um ou dois meses, depois regressam às tribos, onde realizam atividades ministradas pelos professores e estudam de forma autônoma, em grupo ou individualmente. O Ministério da Educação oferece apoio financeiro para que eles se mantenham nas cidades, sendo tais cursos ministrados por universidades federais, como é o caso da UFMG através da Faculdade de Educação, por exemplo. Um dos critérios para a seleção do estudante é que ele não somente descenda de povos nativos, mas que viva em aldeia e compartilhe de vivências tradicionais próprias da sua cultura.

Cabe destacar, com Ciaramello (2014), que a "escolarização" indígena não é recente no País, tendo começado praticamente com a colonização portuguesa, nas missões jesuítas, nas quais o objetivo era catequizar "os índios", alfabetizá-los em português e "civilizá-los". Em 1910, é criado o SPI, Serviço de Proteção ao Índio, que nada mais era que a busca estatal por inserir os nativos no processo de interiorização econômica do Brasil, no caso, por meio da educação escolar. Posteriormente, sob a Ditadura Militar, a escolarização indígena acontece por meio de um programa internacional, o SIL (Summer Institute of Linguistic), com a proposta não de aceitar as diferenças, mas com viés basicamente missionário católico e, sobretudo, protestante em relação aos nativos.

A partir da década de 1960, a Antropologia volta-se com mais intensidade aos estudos etnológicos dos povos indígenas, com destaque para cientistas como Darcy Ribeiro, por exemplo. Dentre as diversas temáticas de interesse dos pesquisadores estava a educação informal, isto é, aquela que se dá nos rituais religiosos, no seio das aldeias, nas práticas de caça, pesca, de extrativismo, ritualísticas. Porém, a Antropologia concedia pouca atenção às práticas educacionais formais, (escolares). Esta permanecia mormente sob atenção das/os ativistas, ONGs, professoras/es, pedagogas/as ou servidores públicos de órgãos como FUNAI, mostrando considerável clivagem entre aqueles que discutiam a educação espontânea e cotidiana e os que praticavam (mas pouco teorizavam) a educação escolarizada dos nativos.

Segundo Silva (2001), o cerne do problema do encontro entre as duas áreas - Antropologia e Educação - é a possibilidade de um tratamento antropológico da educação escolar dos indígenas que lide não apenas com o referencial teórico da Etnologia sul-americana atual, mas também com temas caros à Educação e à Pedagogia. Uma temática central nessa proposta diz respeito às diferenças dos modos de pensar do ameríndio em relação à sociedade ocidental, sobretudo no que concerne à oposição natureza/cultura e ao conceito de ser humano. A pesquisadora ainda menciona que a organização das escolas indígenas no Brasil teve início em meados da década de 1970, a partir dos movimentos sociais pela causa indígena, dando origem à chamada Educação Diferenciada.

Um marco nesse processo ocorreu em 1994 com a criação do Programa de Educação Escolar Indígena, cujas diretrizes foram postas em prática dois anos depois, com a publicação da Lei de Diretrizes e Bases da Educação, quando a escolarização passou a levar em conta os modos de vida, valores, tradições e marcadores de tempo próprios dos indígenas, respeitando-se as diversidades étnicas. Por fim, cabe destacar que a Educação Básica Indígena é oferecida em instituições educacionais inscritas em seus próprios territórios e, por isso, requerem pedagogia particular em respeito às peculiaridades étnicas e históricas de cada povo. Também é imprescindível que as aulas sejam bilíngues, isto é, em língua portuguesa e na língua nativa da aldeia onde se situa a escola. Além disso, assim como as escolas quilombolas, tais unidades de ensino têm autonomia para definir calendários, festividades e feriados próprios conforme suas especificidades culturais e/ou seus modos econômicos tradicionais.

No que concerne à discriminação contra o sexo feminino e contra homossexuais, mulheres e homens, nos contextos educacionais formais, vale lembrar que o sexismo e a LGBTTfobia ${ }^{2}$ são expressões do preconceito e da discriminação presentes nas discussões políticas e nos movimentos sociais desde o fim do século XX. Paralelamente, alguns profissionais escolares também vêm observando que o preconceito de gênero é um dos aspectos que mais afetam o desempenho daqueles que frequentam a escola (FREITAS, 2018). Dentre as práticas discriminatórias mais comuns, destacam-se a LGBTTfobia, que é, resumidamente, o preconceito e a discriminação que têm como suporte a orientação sexual e/ou a identidade de gênero do outro, sendo dirigidos a pessoas e/ou grupos homossexuais, bissexuais, travestis e transexuais.

${ }^{2} \mathrm{O}$ termo LGBTTfobia é mais amplo e engloba as diferentes práticas e desejos sexuais, bem como identidades de gênero que não se enquadram na heterossexualidade e na dualidade feminino/masculino imposta aos sujeitos na cultura ocidental há milênios. Para melhor esclarecimento dos termos, ver o editorial de uma jornalista militante em: http://www.ihu.unisinos.br/78-noticias/579113-por-que-e-melhor-usar-o-termo-lgbtfobia-no-lugar-de-LGBTTfobia. Educação em Revista|Belo Horizonte|v.37|e26064|2021 
De acordo com Marcella Gomes et al. (2014), o sexismo é o preconceito e a discriminação baseados no sexo, geralmente dirigidos às mulheres, sendo a misoginia a modalidade mais comum, isto é, a rejeição por aquilo que diz respeito ao sexo feminino. Especialmente as estudiosas feministas pósestruturalistas vêm mostrando que as culturas escolares tendem a tecer expectativas, assim como a tratar os indivíduos de sua comunidade (alunos, docentes, funcionários e pais) segundo concepções dominantes de classe social, raça/etnia, religião, orientação sexual. No caso do gênero, historicamente a escola tem contribuído para produzir e reforçar muitas desigualdades e preconceitos (LOURO, 2003). Tal ethos marginaliza os que não se adequam às regras hegemônicas e autoritariamente estipuladas.

Dessa forma, rotineiramente, a escola ratifica e convive com violências simbólicas e, não raro, físicas, de caráter misógino e LGBTTfóbico. Isso quer dizer que as instituições de ensino frequentemente promovem esses preconceitos e discriminações não intencionalmente, visto que certos padrões de gênero estão assaz incorporados no cotidiano da cultura escolar que as/os profissionais que ali atuam, muitas vezes não se dão conta de estarem pondo em prática ações discriminatórias. Ademais, faz-se mister pontuar que mulheres, transexuais e homossexuais pobres e/ou negras vivenciam diferentemente essa violência se contrastados a homossexuais/transexuais e mulheres das classes altas e/ou brancas, por exemplo.

Discriminação e preconceito são termos relacionados, podendo afetar simultaneamente o mesmo indivíduo, porém, não são a mesma coisa. Preconceito designa as construções culturais e as representações culturais e/ou psíquicas negativas para com indivíduos e/ou grupos tidos como inferiores. Discriminação, por sua vez, refere-se à concretização, no âmbito das interações sociais e/ou institucionais (incluindo-se os sistemas educacionais), de atitudes negativas e/ou agressivas advindas de mentalidades e/ou predisposições preconceituosas, gerando a violação dos direitos humanos fundamentais; em outros termos, discriminação seria a materialização de atitudes, valores, ideias, concepções e ethos preconceituosos.

$\mathrm{Na}$ escola, essas discussões são ainda praticamente tabus, embora pesquisas sobre relações de gênero, sexualidade e aprendizagem (neste caso, informal) tenham começado ainda na década de 1950 com as antropólogas norte-americanas Ruth Benedict e Margaret Mead, pesquisadoras da corrente conhecida como Cultura e Personalidade (GOMES et al., 2014) e ex-alunas de Franz Boaz. A heteronormatividade, como regra individual para a orientação sexual, diz respeito à sua institucionalização como padrão cultural, político, econômico, jurídico e religioso - em uma palavra, social. Na educação escolar, tal processo ocorre explícita e, sobremodo, implicitamente.

A institucionalização da heterossexualidade é legitimada em todos os campos sociais: desde a família, passando pela mídia, até as leis e a escola. Um dos aspectos educacionais mais nocivos disso é que o binarismo homossexualidade/heterossexualidade funciona como critério para avaliação da dignidade dos indivíduos e para facilitar ou impedir o acesso das pessoas aos bens materiais (um emprego, p. ex.) e simbólicos, como é o caso de certos conteúdos curriculares e mesmo teorias científicas.

Nesses termos, faz-se urgente a reavaliação das práticas e dos discursos educacionais (didáticas e currículos), pois a LGBTTTfobia é uma construção social mais abrangente, decorrente da sociedade e que atravessa outras instâncias socializadoras (igreja, família, esportes), não raro sendo reproduzida nas instituições escolares, sustentando a lógica dicotômica sexista e propalando a exclusão de certos sujeitos. De acordo com Louro (2003), este padrão sociocultural binarista classifica, hierarquiza, subordina e exclui o polo constituído pelo sexo feminino, pelos/as homossexuais, trans e bissexuais.

$\mathrm{Na}$ cultura escolar, a LGBTTfobia geralmente se materializa em agressões verbais e físicas, gerando isolamento, transtornos e sofrimento psíquico, causando evasão escolar, repetência ou até aversão em relação àquele espaço, provocando traumas em relação às instituições de ensino que podem durar toda a vida. No que tange aos docentes, a conduta mais comum é considerar que chacotas dessa natureza são brincadeiras inocentes, negligenciando as situações de bullying ou, o que é mais grave, também tendo condutas violentas (verbais geralmente) contra esses indivíduos.

Há estreita relação entre LGBTTfobia e misoginia, e essa imbricação é alicerçada pelo heterossexismo. Assim, a desigualdade de gênero é construída em nossa sociedade pela oposição entre masculino e feminino. Destarte, a homossexualidade põe em risco a estabilidade fragilmente mantida das identidades sexuais e de gênero, ambas estruturadas pelo binarismo histórica e culturalmente articulado homem/mulher. As relações de gênero (ou relações sociais entre os sexos, na França) dizem respeito às 
diferenças de comportamento, pensamentos, valores, símbolos, papéis sociais, ao exercício do poder e ao acesso aos bens econômicos, entre outros aspectos, criados pelas sociedades a partir das diferenças anatômicas entre mulheres e homens. Dessa forma, feminilidade e masculinidade apresentam-se e são vivenciadas como distintas não por questões biológicas, mas porque as pessoas são educadas, aculturadas, enfim, de maneiras diferentes de acordo com o sexo que lhes é atribuído (GOMES et al., 2014).

Concernente à escolarização especificamente, há muito se reconhece a não neutralidade dos processos de ensino e aprendizagem, ou o caso da suposta afinidade "natural" de meninos para a área de ciências exatas e de meninas para a área de ciências humanas. Embora reais, não são naturais, mas sim fatos culturais construídos pela sociedade. Igualmente, tais construções culturais vêm influenciando a inclusão ou a exclusão de certos conteúdos no ensino ao longo da história. Na micropolítica escolar, geralmente o acesso aos conhecimentos não é o mesmo para todos os indivíduos.

Seus efeitos impõem limitações materiais e simbólicas sobre o quanto e o que um indivíduo poderá aprender de acordo com o sexo, influenciando suas condutas, autoconfiança e oportunidades na vida. Diversas pesquisas ilustram a não neutralidade na interação professor(a)-conhecimento-aluno(a) (LOURO, 2003; FREITAS, 2018). A construção de preferências e de aversões por certas áreas de conhecimento são fenômenos sociopedagógicos, influenciando a inserção ou a exclusão dos sujeitos na sociedade e fazendo com que até hoje exista acesso diferenciado aos conhecimentos de acordo com as relações de gênero prevalentes em dado contexto.

Da mesma maneira que a ciência, as escolas, conforme Louro (2003), em sua micropolítica, também lidam com conhecimentos permitidos ou interditados de acordo com o sexo dos indivíduos. Este acesso discriminador, em geral, não ocorre conscientemente, mas esconde-se em "boas ações" docentes como, por exemplo, partir do pressuposto de que as meninas são mais "frágeis" e devem ser poupadas de certas práticas de Educação Física, ou o contrário, crer que suportar a dor "é coisa de homem" e por isso é natural submeter os meninos a sofrimento físico e/ou psíquico.

As implicações negativas dessas práticas escolares são as de impor limites artificiais (ou seja, são criados, não são biológicos) sobre quanto e o que um indivíduo poderá aprender, influenciando suas condutas e suas possibilidades nos grupos em que se insere. Dessa maneira, as situações escolares são fruto da percepção que a escola tem sobre aqueles que irão ou aqueles que não irão ter acesso a certos saberes. A forma diferenciada de acesso de meninas e de meninos aos conhecimentos e às atividades na escola pode, então, definir padrões de condutas nas trajetórias escolares e influenciar no sucesso e/ou no fracasso escolar e que profissões tenderão a procurar.

Estudos etnográficos, como os de Guedes (2014), revelaram que as falas dos meninos em sala de aula são mais ouvidas e que a curiosidade nos garotos é mais instigada, ao passo que as atividades sugeridas às meninas são mais "previsíveis", isto é, menos desafiadoras; em geral se lhes dão "modelos de encaixe" já prontos, que elas deverão apenas preencher ou "seguir o modelo", sem que sejam incitadas a construir o conhecimento. Desse modo, são várias as situações em sala de aula em que acontece um tratamento aos dois sexos de forma diferenciada, discriminação esta geralmente irrefletida e não proposital, já que internalizada desde a infância (GOMES et al, 2014).

Ainda sobre a articulação do preconceito LGBTTffóbico e o preconceito de gênero, o antropólogo Richard Parker (2002) é pródigo em demonstrar como a desigualdade de gênero é mais ostensiva no Brasil com homossexuais vistos como femininos, com lésbicas vistas como masculinas e com transexuais femininos e masculinos em vários ambientes institucionais, como é o caso da escola. Com efeito, se hoje são inaceitáveis piadas com negros ou sobre o holocausto judeu, por exemplo, ainda se admite, sem maiores problemas, chacotas envolvendo a orientação sexual, como pode ser verificado nas aulas de Educação Física em particular e nos esportes em geral; ou então o não cumprimento da normativa de utilização do nome social nas instituições de ensino.

Com efeito, o combate à LGBTTfobia e à misoginia na educação escolar pede, além do questionamento dos pressupostos machistas que já vêm sendo criticados pelo feminismo, que se interrogue também a heterossexualidade compulsória como regra cultural de normalidade. Estudos com estudantes do Ensino Médio revelaram que, em uma escala de mais ou menos grave, "bater em homossexuais" é visto como algo menos sério que o envolvimento com drogas ou o roubo, por exemplo (Comitê Nacional de Educação em Direitos Humanos, 2003, apud GOMES et al., 2014). Assim, as políticas públicas voltadas à educação têm como papel discutir os preconceitos culturalmente produzidos 
e efetivar a real equidade entre os indivíduos, questionando as normas quando estas se mostram autoritárias, violadoras e opressoras.

Em relação às questões étnico-raciais afro-brasileiras, a educação no Brasil é apontada, seja pelas pesquisas acadêmicas, seja pelos movimentos sociais negros, como um tempo/lugar onde permanecem históricas desigualdades raciais e sociais, segundo Nilma Lino Gomes (2011). Tal configuração demanda, por parte do Estado, a adoção de práticas e de políticas de superação da desigualdade socioeconômica e do racismo na educação, sendo que algumas práticas neste sentido começaram a ser implantadas de modo mais sistemático no País apenas a partir da década de 2000.

Conforme Marcus Fonseca (2016), o Brasil particulariza-se por ser uma das maiores sociedades multirraciais do planeta, abrigando significativo contingente de negros e de afrodescendentes. Tal característica étnico-racial é alvo de estudos e ações por parte do movimento negro e de cientistas que se interessam pelas relações raciais no País, entendendo como negro o conjunto das populações preta e parda. A distribuição dos índices de escolaridade, segundo a cor dos brasileiros, evidencia que não são verificadas distinções significativas entre "pretos" e "pardos" que justifiquem que tais grupos sejam analisados separadamente.

Em tal cenário social, cultural, histórico, político e econômico, os sujeitos negros e negras brasileiros articulam suas identidades que, como tais, são resultado de um processo individual e social simultâneo, materializando-se no cruzamento com outras categorias como gênero, religião, ambiente rural ou urbano, classe e faixa etária, em um contexto marcado por um racismo ambíguo e de permanente desigualdade social. A partir dos movimentos negros, raça é aqui compreendida como uma construção social, histórica e cultural de classificação dos grupos e dos indivíduos, não obstante pesquisas mais recentes do campo da genética tenham mostrado ser impróprio se falar em "raças" para o conjunto da humanidade sob o ponto de vista biológico.

Diversos estudos têm mostrado a luta da população negra brasileira na superação do racismo ao longo do tempo (GOMES, 2011; FONSECA, 2016), seja na forma de quilombos, dos movimentos abolicionistas, através de associações e de imprensa própria. Contudo, é nos anos 1980, durante a redemocratização, que se dá um novo modo de atuação política dos movimentos negros no País. A partir daí, intelectuais e militantes passam a questionar o exclusivo enfoque de classe social sobre as ações e reflexões acerca da desigualdade social. Passam a criticar as instituições públicas, as esquerdas e os movimentos sociais até então existentes sobre o caráter omisso de suas práticas em relação à influência das questões raciais na permanência da miséria e da exclusão.

Assim como as mulheres, com exceções, os negros permanecem sub-representados e inseridos de forma subalterna nos escalões mais altos do poder das grandes corporações e das instituições públicas. Logo, nas demandas levadas a cabo pelos ativistas, uma temática sempre esteve presente em razão do seu caráter estratégico na sociedade: a educação. No entanto, os ativistas e intelectuais negros têm ciência de que a educação não é a única saída para todas as mazelas sociais, não obstante desempenhe importante papel no processo de autoconhecimento e contribua para a formação de sujeitos que podem vir a ocupar espaços de poder econômico e/ou político, além do que ela é usada pelo mercado de trabalho como quesito de inclusão/exclusão social.

Segundo Gomes (2011), as pesquisas elaboradas nas últimas décadas indicam que o campo educacional vem produzindo e reproduzindo um quadro sistemático de desigualdades étnico-raciais. Isso foi sendo evidenciado mais fortemente quando, a partir dos anos 1970, com a consolidação dos cursos de pós-graduação em Educação, grupos de intelectuais negros das universidades públicas passam a produzir conhecimento sobre as questões étnico-raciais no País. Dentre as questões abordadas pelos primeiros estudiosos estão a discriminação racial veiculada pelos livros didáticos, a urgência de inserção de assuntos raciais e ligados à História da África nos currículos e o silêncio em relação à discriminação aberta e, especialmente, à velada nas escolas. Consequentemente, os primeiros teóricos apontaram como a escola era uma instituição reprodutora e ratificadora do racismo no Brasil.

Isso resultou em críticas às políticas educacionais e desencadeou pressões sobre o Ministério da Educação e sobre os gestores das instituições de ensino e das escolas públicas acerca do papel da educação na superação do racismo na sociedade (GOMES, 2011). Ademais, mesmo que na elaboração da Constituinte de 1988 e da Lei de Diretrizes e Bases da Educação (Lei n. 9.394/1996) tenha havido ampla participação dos movimentos negros, os debates realizados em torno desta temática foram 
esvaziados de seu conteúdo político por parte dos parlamentares da época. Além disso, como pontua Fonseca (2016), a entrada de negras e negros nos cursos de pós-graduação dinamizou as temáticas de investigação, especialmente no campo das ciências humanas; processo similar se deu em relação aos estudos sobre mulheres a partir da década de 1970 e estudos sobre a homossexualidade nos anos 80.

Essa situação apenas foi revista e alterada quando acontece a sansão da Lei n. 10.639/2003, tornando obrigatório o ensino da História da África e das Culturas Afro-Brasileiras nas escolas privadas e públicas nos ensinos Fundamental e Médio. Portanto, até os anos 1990, a luta do movimento negro no Brasil, no que tange à educação, demandou a introdução da questão racial no seio das políticas públicas para a educação universal, focando especialmente a educação básica e o acesso ao ensino superior (FONSECA, 2016). No entanto, quando o movimento negro percebeu que a educação oficial não se comprometia com a alteração da subordinação racial que imperava no País há séculos, suas reinvindicações subiram de tom.

Começam a se configurar lutas por Ações Afirmativas inspiradas nas conquistas por direitos civis dos afro-americanos, iniciativas que, no fim da década de 1990, se concretizam em muitos contextos universitários. Nesse sentido, as demandas dos movimentos negros em relação à educação passam a girar em torno de dois polos principais: o acesso à educação formal, desde a básica à universitária, como um direito social, e a defesa do direito à diversidade cultural e religiosa. Em 1997 é introduzido nos Parâmetros Curriculares Nacionais (PCNs) o tema transversal chamado Pluralidade Cultural. Entretanto, conforme Gomes (2011), a temática racial continuava se diluindo no discurso da pluralidade cultural e no folclorismo, destituindo seu ensino de caráter político e isento de crítica ao racismo arraigado na sociedade brasileira.

Outra crítica do movimento negro é que os PCNs apresentam caráter relativamente conteudista, pressupondo que a inserção de "assuntos socioculturais" transversalizando o currículo seria suficiente para tratar pedagogicamente temas relativos à discriminação racial. Reforçados pelos dados oficiais elaborados pelo Instituto de Pesquisa Econômica Aplicada (IPEA), inúmeras entidades do movimento negro vislumbraram que aquele era o momento de introduzir as ações afirmativas no País e de denunciar que a educação vinha sendo um fenômeno social que contribuía para a permanência das desigualdades raciais (GOMES, 2011).

Assim, foi exigida das políticas educacionais a promoção da equidade como uma das formas de se garantir aos diversos coletivos a efetivação da igualdade de direitos e de oportunidades. Uma igualdade alicerçada no reconhecimento e no respeito à diferença e que significasse real superação das injustiças históricas advindas da discriminação e da exclusão racial. A partir de 2003, esse debate é aprofundado, e, pela primeira vez no governo federal, é instituída uma secretaria especial para a promoção da igualdade racial. No Ministério da Educação, em 2004, é criada a Secretaria de Educação Continuada, Alfabetização e Diversidade (SECAD), recentemente extinta pelo governo de extremadireita empossado em $1^{\circ}$ de janeiro de 2019 , o que representa enorme retrocesso do Brasil em relação a ações concretas no sentido de mitigar o racismo estrutural.

"É neste contexto que, finalmente, é sancionada a lei n. 10.639, 01/2003, alterando a lei n.9.394/96 - Lei de Diretrizes e Bases da Educação" (GOMES, 2011, p. 115). Todavia, sua efetiva concretização em currículos e em práticas educacionais vem sendo um dos desafios dos movimentos sociais negros no presente. Em março de 2008, esta lei foi alterada, passando a contar também com a história e a cultura dos indígenas brasileiros e se configurando como uma política educacional de Estado, já que é uma Lei de Diretrizes e Bases da Educação, e não uma legislação particular da população negra. Nesse sentido, possui abrangência nacional e deve ser implementada em todas as instituições escolares particulares e públicas do País, bem como pelas universidades, em todos os níveis de ensino.

A efetivação desta lei depende, no entanto, de maior mobilização da sociedade civil no sentido de que o direito à diversidade étnico-racial seja realmente garantido nos currículos escolares, nos projetos político-pedagógicos e na formação de professores, por exemplo. É uma modalidade de política até então inusitada no Brasil, pois é voltada para a valorização da memória, da cultura e da identidade negra através da educação. Contudo, Gomes (2011) pondera que a existência da legislação não significa que ela automaticamente se espraie nas práticas escolares, porque as diretrizes e a lei se confrontam com práticas cotidianas discriminatórias e com um imaginário coletivo preconceituoso, há séculos arraigados na sociedade brasileira e que se materializam no funcionamento e na estruturação da educação do País, 
com a crença na democracia racial, no racismo cordial, na ideologia do branqueamento e na naturalização das desigualdades socioeconômicas.

A mudança nesse quadro implica inserir a questão racial nas metas educacionais mais gerais do Brasil de maneira contundente e crítica, indo além da adoção de projetos pontuais e descontínuos voltados para temas étnico-raciais. Gomes (2011) aponta que o ideário republicano nacional ainda é resistente sobretudo no que diz respeito à diversidade, historicamente sendo marcado por políticas públicas universalistas e pretensamente neutras. Dessa forma, a escola ainda contribui pouco para a compreensão da diversidade étnico-racial do Brasil e para o entendimento de como isso é uma questão política que se imiscui pelas relações de poder, pelo mundo do trabalho, do conhecimento e como classifica e hierarquiza social e racialmente a sociedade.

Finalizando, acerca das relações metodológicas entre Educação Escolar e Antropologia, a etnografia, método antropológico por excelência de coleta de dados por meio da vivência nos grupos, vem se mostrando útil para quem pesquisa as práticas educacionais concretas, como é o caso, por exemplo, da educação quilombola (CARRIL, 2017). De fato, um dos estudos pioneiros da utilização dos procedimentos etnográficos na educação realizada em quilombos foi o empreendido junto aos Kalungas do norte de Goiás. A investigação partiu de uma ação pedagógica cujo escopo era a afirmação da identidade negra e da história local em escolas da comunidade, tendo sido produto do trabalho da equipe interdisciplinar do projeto - professoras/es, antropólogas/os, pedagogas/os -, dos membros da comunidade e dos estudantes.

Neste caso específico, pretendeu-se contribuir com uma apreensão mais complexa e menos folclorista dessa coletividade, visão esta atravessada pelos fenômenos pedagógicos e que colaborasse para o entendimento das dinâmicas peculiares da escola comunitária quilombola, permitindo a identificação e o aprofundamento das categorias de representações e de práticas coletivas que alicerçam as sociabilidades, os conflitos e a transmissão das tradições afro-brasileiras naquele contexto. Para isso, foi central a utilização dos "[...] instrumentais teóricos e metodológicos da antropologia - disciplina acadêmica cuja pretensão é (apenas) analisar e conhecer - para compreender e contribuir com a pedagogia, ou seja, uma prática que visa, antes de tudo, intervir” (GUEDES, 2014, p. 7).

\section{CONSIDERAÇÕES FINAIS}

O cerne do pensamento antropológico - o ser humano interrogar-se coletivamente em comparação a outros e a indagação acerca de outras culturas - existe desde a Grécia Antiga, entre todos os povos, como maias ou chineses, por exemplo; porém, a Antropologia como ciência surgiu apenas em meados do século XIX na Europa. A principal particularidade da Antropologia em relação às outras ciências humanas, como Psicologia ou Sociologia, é se voltar para a cultura vivida e empregar o método comparativo nos estudos, não no sentido de tentar reduzir uma sociedade à outra, mas de entender que o que é familiar e o que é estranho é, afinal, uma questão relativa: depende do lugar de quem observa o outro.

A educação, por seu lado, não é um fenômeno neutro e imparcial como geralmente se julga. Questões políticas e culturais mais amplas atravessam permanentemente os processos de ensino e de aprendizagem; alguns desses processos aqui trazidos, como a escola indígena, a cultura afro-brasileira e as questões de gênero e de orientação sexual, fazem que com determinados indivíduos tenham acesso ao conhecimento de forma diferenciada, ainda que isso não esteja prescrito nos documentos e políticas públicas escolares oficiais.

Sendo assim, o texto destacou a centralidade dos processos educativos no combate aos inúmeros preconceitos - racismo, sexismo e LGBT'Tfobia, entre outros -, promovendo práticas que privilegiem a construção de uma sociedade equânime e com cidadãos respeitosos (não apenas tolerantes) em relação aos comportamentos e aos grupos diferentes. A escola - profissionais, os pais e o alunado ainda reflete o desconhecimento social generalizado de que discriminar é uma forma de violência. Além disso, há relativo despreparo dos/as educadores/as para lidar com tais situações no cotidiano. Nesse caso, o olhar antropológico pode contribuir no sentido de levar a uma familiarização com o que é considerado "estranho" e "exótico" e a um estranhamento daquilo que é dado como "familiar" e "normal". 
Por seu turno, o campo educacional, ao recorrer à Antropologia, contribui para que esta deixe de ficar encerrada na academia e distante dos problemas concretos da sociedade em que é produzida. Com efeito, a interface entre campos de conhecimento, como a Antropologia da Educação aqui propugnada, favorece que as teorias e os acadêmicos que as elaboram se engajem politicamente, ajudando a desconstruir a imagem que muitas vezes se tem de campos como o antropológico ou o filosófico, de que não podem ter aplicação prática e que devem ser voltados somente a abstrações contemplativas acerca do real, raramente intervindo no mesmo. Entretanto, aqui não se advoga que áreas como a Antropologia ou a Filosofia DEVEM, obrigatoriamente, ser instrumentais, mas sim que PODEM ser práticas, especialmente quando em interação com outros campos, como a já citada Pedagogia, a Comunicação ou o Serviço Social, por exemplo.

Ademais, foi visto que ainda permanece entre alguns agentes educacionais uma tendência à hierarquização das desigualdades sociais, portanto, a desigualdade racial é colocada como dependente da desigualdade econômica. Como consequência, a atuação isolada de alguns professores é até hoje a prática mais comum nas escolas no sentido de uma postura mais incisiva em relação às desigualdades étnicoraciais, por exemplo.

Nesses termos, qualquer investigação sobre as políticas educacionais no Brasil não pode negligenciar a questão da diversidade e das desigualdades étnico-raciais, de gênero e sexuais. Por fim, cabe o enunciado de Gusmão (2015, p. 34) não como asserção conclusiva, mas como interrogação e provocação para investigações futuras que congreguem Antropologia e Educação: "Na verdade, no Brasil, na primeira metade do século XX, mais que a antropologia, foi a sociologia que olhou mais detidamente a educação [...]. A ausência ou escassez na tradição de estudos antropológicos com o tema educação no caso brasileiro talvez sejam algo a ser considerado".

Em síntese, preconiza-se que, assim como se passou com a Sociologia, a Antropologia também se volte mais para a Educação e que esta, principalmente em sua aplicação prática, no caso, a educação escolar, se enriqueça ainda mais das contribuições antropológicas, como veio fazendo no que concerne à Sociologia e à Psicologia. Em uma perspectiva mais pragmática, a Antropologia pode levar para a educação, em tempos de enrijecimento das posturas pedagógicas, um olhar mais inclusivo e relativista, isto é, a percepção de que não existe somente um padrão de comportamento, de conhecimento ou de pensamento, que a visão de mundo do meu grupo é somente uma e não "a" visão de mundo, e que os sujeitos não devem ser avaliados por sua condição sexual, de gênero ou em função de sua raça/etnia.

\section{REFERÊNCIAS}

BOAS, Franz. Antropologia Cultural. 2 ed. Rio de Janeiro: Zahar editores, 2005.

BOURDIEU, Pierre.; PASSERON, Jean-Claude. Reproduction in education, society and culture. London: Sage, 1990.

BOURDIEU, Pierre. Cosas dichas. Buenos Aires: Gadisa, 1988.

CARRIL, Lourdes de F. B. Os desafios da educação quilombola no Brasil. O território como contexto e texto. Revista Brasileira de Educação, v. 22, n. 69, p. 539-564, abr./jun. 2017.

CIARAMELLO, Patrícia R. Escolarização indígena, cultura e educação. Educação, Sociedade \& Cultura, n. 41, p. 109-125, 2014.

DAYRELL, Juarez. A escola como espaço sócio-cultural. Belo Horizonte: Editora UFMG, 2001.

FORQUIN, Jean-Claude. Escola e Cultura. As bases sociais e epistemológicas do conhecimento escolar. Porto Alegre: Artes Médicas, 1993.

FONSECA, Marcus V. A história da educação dos negros no Brasil. Niterói: Editora UFF, 2016. 
FREITAS, Marcel A. Mulheres cientistas. Percursos e percalços a partir da realidade da UFMG. Belo Horizonte: Conhecimento, 2018.

GOMES, Nilma L. Diversidade étnico-racial, inclusão e equidade na educação brasileira: desafios, políticas e práticas. Revista Brasileira de Política e Administração em Educação, v. 21, n. 1, p. 109-121, jan./abr. 2011.

GOMES, Marcella M.; BROCHADO, Mariah; LIPOVETSKY, Nathália (orgs). Curso de Aperfeiçoamento Paideia Jurídica na Escola: educação em direitos humanos para uma consciência jurídica cidadã. Belo Horizonte: CAED/UFMG, 2014.

GUEDES, Simoni L. Por uma abordagem etnográfica dos contextos pedagógicos. In: GUEDES, Simoni L.; CIPINIUK, Tatiana A. Abordagens etnográficas sobre educação: adentrando os muros das escolas. Niterói: Alternativa, 2014, p. 7-10.

GUSMÃO, Neusa M. M. Antropologia e educação: um campo e muitos caminhos. Linhas Críticas, v. 21, n. 44, p. 19-37, jan/abr. 2015.

LAPLANTINE, François. Aprender Antropologia. 8. ed. São Paulo: Brasiliense, 1994.

LOURO, Guacira L. Corpos, gênero e sexualidade: um debate contemporâneo na educação. Petrópolis: Vozes, 2003.

PARKER, Richard. Abaixo do Equador. São Paulo: Record, 2002.

PEIRANO, Mariza. Etnocentrismo às avessas: o conceito de 'sociedade complexa'. Dados - Revista de Ciências Sociais, v. 26, n. 1, p. 97-115, 1983.

SILVA, Aracy L. Uma 'Antropologia da Educação' no Brasil? Reflexões a partir da escolarização indígena. In: SILVA, Aracy L.; FERREIRA, Mariana K. L. (orgs). Antropologia, História e Educação. A questão indígena e a escola. 2 ed. São Paulo: Global, 2001, p. 29-43.

TADDEI, Renzo; GAMBOGGI, Ana Laura. Education, anthropology, ontologies. Revista Educação e Pesquisa, v. 42, n. 1, p. 27-38, jan./mar. 2016.

TOSTA, Sandra; ROCHA, Gilmar. Antropologia \& Educação. Belo Horizonte: Autêntica, 2009.

Submetido: $30 / 01 / 2020$

Aprovado: $24 / 01 / 2021$ 